\title{
Impact of Customer, Environment and Company Side Uncertainty and Risk on Logistical Performance: An Analysis on Pakistan Courier Industry
}

\section{Sehran Akram ${ }^{1 *}$, Danish Ahmed Siddiqui ${ }^{2}$}

${ }^{1}$ Research Scholar, Karachi University Business School, University of Karachi, Karachi, PAKISTAN

${ }^{2}$ Associate Professor, Karachi University Business School, University of Karachi, Karachi, PAKISTAN

Corresponding Contact:

Email: sehranakram@gmail.com

Manuscript Received: 09 Feb 2019 - $\quad$ Revised: 25 Mar $2019 \quad$ - $\quad$ Accepted: 02 April 2019

\begin{abstract}
This study investigates the supply chain uncertainty and risk on the logistics performance of Pakistan courier industry. The three main constructs under the supply chain uncertainty are company side, customer side, and environmental side risk uncertainty. The data has been gathered by means of a questionnaire with a seven scale measurement from which 200 responses have been gathered from the managers, staff members to higher-level managers of the Pakistan Courier industry. The study has used structural equation modeling for the data analysis. The study found that there is a significant relationship between the company-side, customer-side and environmental side risks on the logistics performance of the Pakistan courier industry. The statistical analysis clearly reveals that the courier has been facing the major risk that could affect the health and performance of the company, therefore, it is important to focus on the logistics performance as it is the most notable factor to make courier industry efficient and directly interrelates with the company progress and success.
\end{abstract}

Key Words: Customer, environment, risk, uncertainty, logistics, SEM

\section{INTRODUCTION}

In the field of business management, the topic of supply chain and uncertainty has progressively become one of the most vital areas to study. Only a few scholars have offered an in-depth explanation of the area of uncertainty so far. Mostly the business decision is related to the uncertainty element. Numerous business studies heavily relied on the risk management theory and disaster management theory to address the uncertainty in business management. According to the interview took by Shapira (54\%) from managers they uttered that, mainly managers consider uncertainty as a factor in risk. Managers treat uncertainty as an important aspect of risk. Uncertainty in business is a situation where managers are 
merely unable to detect the various deviations and unable to assess the likelihood of their occurrence. The risk is basically something that will happen in future but what will be the intensity and after effect, no one knows in a company, whether it has a micro level effect or a macro level effect. The risk is involving in our everyday life and professional life. Likely risks are also involved in big industries like; manufacturing, plastic industry, FMCG, the pharmaceutical industry and so in logistics etc. Sometimes incomplete information shared within company partners create a negative impact on the logistical performance.

This has particularly resulted in the difficulties in the business operations, mainly in the supply chain networks. The unstable environment today has led the supply chain to face huge uncertainties and risks in the global world. This has resulted in creating a number of obstacles for the supply chain networks in attaining the preferred logistic performance subjected to timely delivery, increased customer satisfaction, and improved efficiency. Hence, the impacts of supply chain uncertainty and risk on the performance of logistics performance are often similar. (Tang, CS, 2006) States that risks in the SC are inherent uncertainties: in other words, managers have to face and manage them. Figuring about risk as, what will happen next is immeasurable for company managers. But they figure about how the distribution looks like. There are many SC risks that relate to the uncertainty and cannot be apart from other. The risk may influence the performance of logistics from the on-time delivery, freight safety, information, and customers. The uncertainty raises the possibility of risk mainly in the third party logistics sector which is the core focus of the study. Today, every other company is making use of the third party logistics (3PL) to deliver and handle the logistics operations in the supply chain and among these, the courier industry is the key player and the rapidly growing sector. The courier industry of Pakistan has been facing some major uncertainties that are disrupting their logistic performance and that as a result needs core attention to provide a pathway to the courier industry of Pakistan to run their operations smoothly by identifying the major components of supply chain uncertainty.

A courier company is a less than truckload (LTL) third-party logistics (3PL) carrier. 3PLs are engaged into dissimilar types including freight forwarders, courier companies and other companies that integrate \& offer subcontracted logistics and transportation services. In Pakistan, there are many issues like political instability, road infrastructure, buildings etc. due to which these courier service providers somehow face the issue of delivering in some certain areas of Pakistan of the parcel on time. In today's era delivery from courier is different from traditional rail, sea, road or air transport, courier delivery offers door to door fast delivery, and customers may be directly involved in the delivery processes.

Now customers are also given the tracking numbers to keep the check on the parcel they requested for delivery. Functions of logistics are being outsourced to the service providers external with the purpose of obtaining economic, technological, and strategic advantages. To provide a spontaneous understanding of the impacts of supply chain uncertainty and risk on the logistics performance in the courier industry, this paper presents an empirical study of supply chain uncertainty and risk in the Pakistan courier industry by examining the impacts of both supply chain uncertainty and risk simultaneously on the logistics performance. The quantitative methods are deployed to analyze the impacts of supply chain uncertainty and risk on the logistics performance.

\section{Problem Statement}

Within supply chains risk of uncertainty has augmented and risk is a result of the internal and external uncertainties that affect the supply chain (Rodrigues et al., 2008). According to 
some authors, uncertainty is a concerning problem in the supply chain and logistics industry.

There were some limitations in the earlier studies that highlight SC collaboration and strategic implication in making supply chain better. The area of supply chain collaboration have not been given much attention in the previous studies and neither its benefits have been highlighted in the previous literature which makes it important to explore this area of supply chain in the present study in order to have enhanced productivity and profitability (Rani, 2015). The area of study has not taken place in Pakistan courier industry up till now which is a major gap. Logistical challenges are present all around the world in with different aspects ranging from the transportation issues to the legislative issues and demographic issues. The difficulties that come under the functions of the logistics industry and processes culminates into the extra loss of the resources, money and time. A similar situation is with the logistics industry of Pakistan. The present empirical study centers on the relationship between supply chain uncertainty and risk and its impact on logistics performance in the courier industry of Pakistan. This study finding will provide an insight into the starting point for an understanding of supply chain uncertainty and risk in the courier industry. In this quantitative study, the SEM (structure equation modeling) approach was used to examine the relationship between supply chain uncertainty risk and impact on logistics performance in the Pakistan courier industry. By exploring the SC uncertainty and risk in the courier industry of Pakistan, it will support other underdeveloped countries in the concerned area to have a pathway to improve their situation of the logistic performance. For instance, issues in green logistics, blocking of traffic, inefficient and poor information sharing between company partners are the most common issues that can be generalized to provide a direction to other countries to seek for the measures to be implemented in their courier industry as well.

The structural equation modeling has been widely used in the literature in many disciplines. The partial least square gives a substitute way to the co-variance based SEM that was particularly designed for the normally distributed data. Path modeling refers to the technique of modeling with minimum demands about the measurement scales, sample sizes and residual distributions. Chin et al. (2003) came up with the two stage approach and identified that if the moderator variable is formative then the paired indicators would not be feasible for the study. This is due to the fact that formative variables does not assumed to reflect about the same constructs i.e., they can be independent of one another and measuring the different factors. The product indicators among the two sets of formative indicators would not essentially tap into the same interacting effect (Chin et al., 2003). It can also be implemented to the models with interaction effects among the latent variables with the reflective measurement models.

The two stage approach uses the PLS path modeling benefit of estimating the latent variable scores. The model is built as follows: In the stage one, the main effect PLS path model is run to get estimates for the latent variable scores. The scores are then calculated and saved for the further analysis. While in the stage 2 , an interaction is built as the element wise product of the latent variable scores of the exogenous variable and the moderator variable. The interaction among the term as the latent variable scores of $\mathrm{Y}$ is then used as the independent variables in the multiple linear regressions on the latent variables of the endogenous variable. The major gap identified in the approach is that the moderating impact is not preferred while estimating the latent variable scores. The two stage approach has the limitation of adequate information that became the key reason to consider the product indicator approach. 


\section{Gap Analysis}

The challenge of logistics is present all around the world in with different aspects ranging from the issue of transportation to the issue of legislation and demographic issues. The hindrances that come under the processes and functions of the logistics industry culminates into the extra loss of the resources, money and time. The same situation goes with the logistics industry of Pakistan.

Pakistan, a developing country is different in many accepts from the courier industry of developed countries, moreover, each country is subjected to different logistic challenges, geographical challenges and most importantly, technological challenges. In advanced countries, there is higher dependence on the technology, however, in Pakistan courier companies have headed towards incorporating technology but not the higher extent. There is a major difference in the roads and regional conditions of countries like Australia and Pakistan which marks as one of the essential factors to count while analyzing the barriers of logistic industry's poor performance (Stewart, 2011). Some other issues that Pakistan logistics industry is has been facing are the railway conditions that are not even able to cater the transportation needs of the passengers is leaving alone the freight transportation in the country. In Pakistan, trucks are used as goods transportation more that are also disintegrated due to the withdrawal of waiver by the government of 16 to 17 percent on trucking (Dawn News, 2011). Above all, the trucking sector is not organized and the corporate sector has always been reluctant to use it. On the other hand, advanced countries have a wide range of transportation and government support system in their industry. From this, we can analyze that Pakistan is different when it comes to challenges faced in logistics industries.

\section{Significance of Study}

The study aims at significantly contributing to enhancing the logistics performance in the courier industry and help companies to find potential solutions through evaluating the customer side risk factors, company side risk factors and environmental risk factors. This will also help other industries facing similar risks and logistic issues. Every industry has been significantly contributing in the economy of Pakistan however, the net inflow of the courier industry has been increasing with the time. Other major industries that are contributing in Pakistan includes manufacturing industry, textile industry and many more. The risk evaluation proves that all the industries have been facing these risks primarily because of tense geopolitical environment, energy dependency, under developed financial system, and lack of managerial implications (Ahmed \& Ahsan, 2011)

Moreover, by analyzing the supply chain uncertainty and risk in Pakistan, it will help other underdeveloped countries in the concerned area to have a pathway to improve their situation of the logistic performance. For example, issues like green logistics, traffic congestion, poor information sharing are the most common ones that can be generalized to provide a direction to other countries to seek for the measures to be implemented in their courier industry as well.

\section{Research Objectives}

Following are the research objectives:

RO1: To examine the impact of supply chain uncertainty and risk on logistics performance.

$\mathbf{R O}_{2}$ : To examine the relationship between the components of the company, customer and environmental side risk on the logistics performance of Pakistan Courier industry.

$\mathbf{R O}_{3}$ : To evaluate the components of supply chain risks and uncertainty that affects the performance of logistics in Pakistan courier industry. 


\section{Research Questions}

Following Research questions will be answered in the study

- Is there a significant impact on supply chain uncertainty and risk on logistic performance?

- Is there a significant relationship among the components of the company, customer and environmental side risk on the logistics performance of Pakistan Courier industry?

- What are the components of supply chain risks and uncertainty that affects the performance of logistics in Pakistan courier industry?

\section{Operational Definitions}

Supply Chain Uncertainty and Risk: Supply-chain uncertainty is an issue with which every practicing manager wrestles, deriving from the increasing complexity of global supply networks (Simangunsong et al., 2012).

Logistic Performance: Logistics is the practice of moving inventory or supplies from a point of origin to a point of use in the most possible efficient way (Kimmons, 2018). The term of logistics performance is linked to the extent to which the firm performs the logistical activities and manages the difficulties coming their way efficiently.

\section{LITERATURE REVIEW}

\section{Uncertainty and Risk}

Uncertainty and risk are said to be the probability of loss or any happening of the event or situation that might be unknown or known to the subject but can create a major loss to the subject. The overall meaning of the term is the idea of being unknown in terms of the time and happening of the event or incident. Seeing the definition of the uncertainty from the economic perspective, it can be stated that it is a business risk that cannot be calculated and whose importance cannot be assumed or assured. In order to discover the major distinction among the two terms which is risk and uncertainty, it was stated in one study that uncertainty is a kind of risk that can be measured and it is defined as the indecision depending on the grounded possibility (Knight, 1921). In another study, it was proposed that in the business setting, the risk is defined as the negative disparity that can affect the productivity of the business including the profits, cost, market stake of the organization that also influences the performance of the business (Miller, 1992).

The occurrence of risk and uncertainty usually takes place due to the fact that the businesses do not have an adequate understanding of what actually is going to happen in the coming future. In the businesses, the best possible methods are used by people in order to perform every analysis, however, despite this, there still lies the possibility of the happening of the unknown event anytime in the future. As stated by Aven (2011) there is an adjacent association among the risk and uncertainty as the probability of risk can be raised and is occurred as a result of uncertainty. It can also be stated that the risk occurrence might also be due to the indecision regarding the future which implies that any unassured event might take place and when such vague events will occur, it will create more damage that might harm huge loss (Waters, 2011).

\section{Supply chain risk and uncertainty}

The risk and uncertainty in the supply chain department have been always one of the burning issues however, this risk seems to be interchangeable. In addition, it has been found that there is a vague and extensive difference in the uncertainty level and risk-taking in the supply chain and it is important to be aware of the differences (McManus \& Hastings, 2006). 
There is a lot of supply chain related risk that causes a high level of uncertainty in the ongoing operations (Rodrigues et al., 2010). According to Jüttner et al., (2003), there are many of the research papers that have a notable impact and academic view on the customer, company and environmental risk that could create an adverse impact on the supply chain performance of the company.

With respect to the theoretical perspective, there are two different concepts of risk and uncertainty and all the aspects seems to be really important for the company management Simangunsong et al., (2012) and Rodrigues et al., (2008). With respect to the uncertainty and risk in the supply chain, there are several complicated concepts and areas that need to be assessed in order to minimize their bad impact on the supply chain at national and international level (Rodrigues et al., 2010). All the types of risk comprise of different uncertainties, sources, drivers and consequences (Christopher \& Lee, 2004). It is an important aspect to identify different techniques related to tackling the supply chain uncertainties in concern with the business and actual industries (Manuj \& Mentzer, 2008). Different business and industries have various drivers and sources related to the risk and uncertainties.

\section{Customer-side Risk and Uncertainty}

For each of the company, the customers have been considered as their assets however, it is important for the company to make their customers gratified and happy to obtain the goodwill with the customers and to make them loyal and retained with the company. There are some of the customers, who seems to be a danger for the company and might be a big risk that affects the company performance. The type of risk seems to be associated between the customers and the company and the operations interrelated to the courier company. It is the foremost duty of the company to deliver good quality goods from the point of origination to the point of destinations. There are two customers that include the consigners and the consignees and parting them away is not an essential tool especially with respect to the reverse logistics when there is a probability of rising (Coyle et al., 2008). This kind of network interrelated risks is considered as customerrelated uncertainties (Jüttner et al., 2003).

\section{Company-side Risk and Uncertainty}

Under this context, some of the problems that mainly arise in the business setting are the sharing of the information which is important for the company followed with the capital to borrow proper and appropriate timely information for the parcel pickup from the customer and dropping it off at the preferred destination. The uncertainty and risk related to information lead to impact the timely information and also it affects the accessibility in the logistics and transport service offers'. The information which is on time helps in the smooth running of the supply chain, especially when it comes to the courier industry as accurate information is very essential for the managers and other staff members. There have been a number of previous studies that have taken into the account the fact that unknown information is the primary reason behind the risk and uncertainty in the supply chain (Murugesan et al., 2013).

\section{Environment Risk and Uncertainty}

Businesses function in the complex environment either it is related to politics, economy, technology or social aspects. If the business is willing to survive in the market it is essential to consider all the above-mentioned factors. The possibility of risk can take place when the connection between the supply chain environment and the external environment takes place. It was argued in a study that environmental risk if overlooked and ignored can create 
great hurdles in the logistic performance of the company (Jüttner et al., 2003). It is difficult to ignore and predict such kind of issue like a car accident might be due to the blocking of the traffic that will have a direct impact on delaying the delivery. This, as a result, culminates into the higher impact on the courier company. This makes the environmental uncertainty a major factor to prefer and considering it as an essential risk and planning as per the condition will result in creating an efficient reactive approach to the problem.

Some of the other external factors that impact the logistic performance in the form of political hindrances such as the laws related to import, competitors and fluctuations with respect to price create complexities in the smooth running of the operations of the supply chain (Prater, 2005). All these external factors are the essential risk factors in the supply chain management in the form of external risk elements that might be a major barrier in the effective logistic performance. Moreover, some of the other uncertainties and risk includes the occurrence of the natural calamities, issue of terrorism and diseases problems. These factors can also create issues in the smooth running of the supply chain operations as they may create delays and a major loss to the entity and its operations. In a study related to the political risk, political unrest and terrorism have the essential role in disturbing the supply chain management Olson and $\mathrm{Wu}(2011)$.

\section{Logistics Performance}

The measurement of the performance has been considered as one of the important keys to obtain the factors of organizational success however, these factors could be measured in two different ways including hard and soft (objectives and responsiveness) evaluation (Chow et al., 1994). All the hard evaluation comprises of the raw statistics, financial status, cost, and commission stats while the idea of soft measures includes self-perception and appraisals. It has been also noted that the analysis and evaluation of the performance could be done by comparing the actual results with the specified objectives (Hudson et al., 1997).

Performance measurement serves as the pointers of the work that is being performed and the outcome attained by that activity (Cohen \& Roussel, 2005). There has been multiple pointers and factors of the logistics performance that have been discussed in the previous literature. Leighton (2012) in his study stated customer service as one significant feature of the logistics performance. The cost of transportation is another essential key pointer of the logistics performance highlighted by Christopher (1998) in his observation. There has a number of empirical investigations that have given their core focus on the concept of service and quality and linked it to the logistic performance stating that the superior service and quality also leads to the effective logistic performance of the company.

In another study, it was suggested that effective logistics performance is an underlying factor and success mantra for the logistics providers (Richard \& Rein, 2004). The study took the transport and freight industry as the dependent variable and defined the nature of the courier industry starting from the origin point to the destination point. The study revealed that the primary variable was the on-time delivery and four main essential attributed were noted for the logistic performance including quality of service, security, dependability, and costs (Helena, 2012). The study formulated the indicators relating to performance on the basis of the hierarchy framework and four main variables were drawn from the framework including the timely delivery, regularity of the freight impairment, regularity of disturbing the functions and suppleness (Pichet \& Shinya, 2008). 


\section{Research Methodology}

\section{Conceptual Framework}

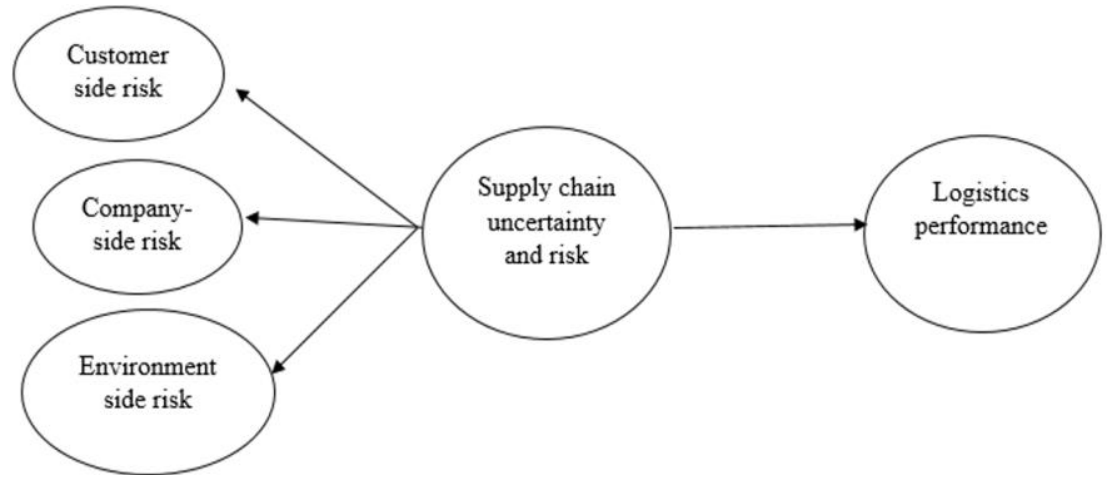

\section{Hypotheses}

Ho1: There is no significant relationship between customer side risk and uncertainty on logistics performance

$\mathrm{H}_{\mathrm{a} 1}$ : There is a significant relationship between customer side risk and uncertainty on logistics performance

$\mathrm{H}_{\mathrm{o} 2}$ : There is no significant relationship company side risk and uncertainty on logistics performance

$\mathrm{Ha}_{\mathrm{a} 2}$ : There is a significant relationship company side risk and uncertainty on logistics performance

$\mathrm{H}_{\text {оз: }}$ There is no significant relationship between environmental risk and uncertainty on logistics performance

$\mathrm{H}_{\mathrm{a}}$ : There is a significant relationship between environmental risk and uncertainty on logistics performance.

$\mathrm{H}_{\mathrm{o4}}$ : There is no significant impact of customer-side risk, company side risk and environmental risk on logistics performance

$\mathrm{H}_{\mathrm{a}}$ : There is a significant impact of customer-side risk, company side risk and environmental risk on logistics performance

\section{Type and nature of the study}

The research is quantitative in nature. Under this approach, the researcher has used the survey as a major tool for the purpose of data collection in order to generate the statistical data to test the hypothesis. The data gathered from the surveys will be later tested to generalize the result for the audience,

\section{Sampling Technique}

For the sampling of the data, the data has been gathered from the individuals who are designated as managers, workers and staff members in the courier industry of Pakistan.

\section{Instrumentation}

For the instrumentation of the data, a seven-point scale questionnaire has been used in the study. The scale has been adapted from the previous and existing researches to measure the multiple constructs of the supply chain management which has been designed by Al-Shboul et al., (2017). 


\section{Sample design}

The sample size preferred in the study is 200 including the managers, staff members, and high-level managers form the courier industry of Pakistan. The sample size has been chosen for the convenience of the participants.

\section{Data Collection}

The primary data has been gathered from the survey where the questionnaire has been used a medium for the primary data collection. The questionnaire has been made with the combination of previous researches and adapted from the base paper of the present study. The questionnaire has been filled online and through emails. The permission has taken from some of the courier industries of Pakistan for the collection of data. The questionnaire has been divided online and by means of the direct electronic data entry method that was used for the recording of answers.

\section{Face and Content validity}

When it comes to questionnaire adaption it is mandatory to measure the quality and validity of the questionnaires from the concern professionals. The validity of this questionnaire has been approved from the supply chain professional and the relevant teacher of supply chain

\section{Statistical Technique}

The statistical method used in the study is Structural Equation Modelling that is incorporated into the PLS software. One of the main tool used in the study is SEM. The tool showed the association between the multiple variables proposed in the study. The tool combines the measurement and structural model into a unified statistical test. The two main methods used to do the SEM are the Covariance method and the Partial Least Square.

\section{DATA ANALYSIS}

This particular section solely presents findings from the survey and research models. Under the different categories, the questionnaire used to measure the supply chain uncertainty and risk. SPSS was used for the initial testing for data screening and pilot testing. The software of smart PLS 3.2.4 used for the testing of convergent validity, content validity, and reliability.

\section{Measurement of Outer Model}

In the subsequent section analysis of data has described. The two criteria were used to validate and reliability of data of outer model that comprises of convergent validity and content validity.

\section{Composite Reliability}

Of the whole measurement model evaluation of composite reliability is done by cross-loadings and genuine interpretation of (CFA) confirmatory factor analysis. Reliability is defined as the measurement of the fact that how many degrees of consistency lies between the multiple variables. The reliability is calculated by composite reliability must higher than 0.700 . In the below-mentioned table, it can be seen that the CR values of all the variables are greater than 0.7 which makes the data and questions reliable enough. As per Chin et al. (2003) it is a requirement to have a strong factor loading within the construct and if any weak construct found in construct model elimination is to improve the outer model. 


\begin{tabular}{|c|c|}
\hline Variables & Composite Reliability \\
\hline Company Side Risk & 0.894 \\
\hline Customer Side risk & 0.862 \\
\hline Environment side risk & 0.87 \\
\hline Logistics Performance & 0.837 \\
\hline
\end{tabular}

\section{Path Model}

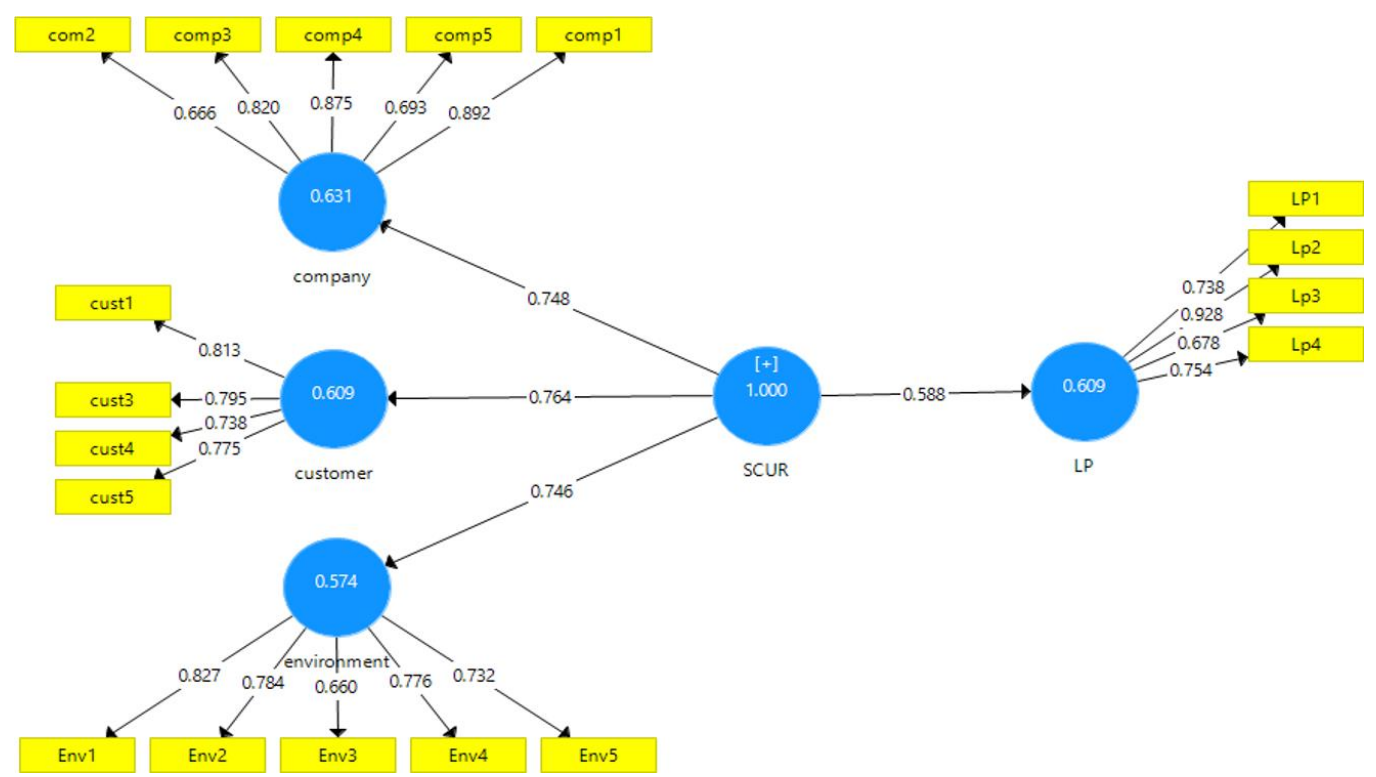

In the above-mentioned figure, the path model results are presented. For the testing of hypotheses in the paper a path coefficient is used. The standardized path estimates $(\beta)$ direction, represent the strength and significance of the relationship between constructs. $\beta$ is considered to be large, medium and small for values of greater than 0.37, 0.24 and 0.1, respectively. In path coefficient, the absolute value should not be greater than 1 . Positive value stands for a positive relationship. The significant path coefficient showed that logistics performance is influenced by the supply chain uncertainty and risk. The findings are presented, and the results show there is a positive significant relationship between supply chain uncertainty and risk and the logistics performance in the Pakistan courier industry.

\section{Factor loadings significant}

These are the factor loadings of the constructs and their $\mathrm{p}$ and $\mathrm{t}$ values are also mentioned

\begin{tabular}{|c|c|c|c|c|}
\hline Construct & Item & Loadings & t-value & p-value \\
\hline \multirow{4}{*}{ Environment side risk } & Env1 & 0.826 & 40.958 & 0.000 \\
\cline { 2 - 5 } & Env2 & 0.784 & 42 & 0.000 \\
\cline { 2 - 5 } & Env3 & 0.659 & 21.725 & 0.000 \\
\cline { 2 - 5 } & Env4 & 0.776 & 26.097 & 0.000 \\
\cline { 2 - 5 } & Env5 & 0.733 & 14.019 & 0.000 \\
\hline \multirow{3}{*}{ logistics performance } & Lp1 & 0.772 & 27.287 & 0.000 \\
\cline { 2 - 5 } & Lp2 & 0.921 & 77.24 & 0.000 \\
\cline { 2 - 5 } & Lp3 & 0.731 & 18.319 & 0.000 \\
\hline
\end{tabular}




\begin{tabular}{|c|c|c|c|c|} 
& Lp4 & 0.679 & 15.218 & 0.000 \\
\hline \multirow{4}{*}{ Company-side risk } & Comp2 & 0.676 & 19.237 & 0.000 \\
\cline { 2 - 5 } & Comp3 & 0.824 & 41.4 & 0.000 \\
\cline { 2 - 5 } & Comp4 & 0.878 & 37.62 & 0.000 \\
\cline { 2 - 5 } & Comp5 & 0.684 & 20.815 & 0.000 \\
\cline { 2 - 5 } & comp1 & 0.885 & 35.469 & 0.000 \\
\hline \multirow{4}{*}{ Customer side risk } & cust1 & 0.813 & 33.039 & 0.000 \\
\cline { 2 - 5 } & cust3 & 0.795 & 48.26 & 0.000 \\
\cline { 2 - 5 } & cust4 & 0.737 & 32.292 & 0.000 \\
\cline { 2 - 5 } & cust5 & 0.775 & 33.407 & 0.000 \\
\hline
\end{tabular}

\section{Convergent Validity}

To measure the convergent validity, it needs to be completed in three phases. Firstly, it's a requirement to have a strong factor loads within the model i.e. greater than 0.7 , the average variance extracted (AVE) needs to be calculated and it should be greater than 0.5 (Fornell and Larcker, 1981) and lastly is the composite reliability (CR) which should be 0.7 or greater than. The following table shows all the above-mentioned assumptions.

\begin{tabular}{|c|c|c|c|}
\hline Variables & $\begin{array}{c}\text { Cronbach's } \\
\text { Alpha }\end{array}$ & $\begin{array}{c}\text { Composite } \\
\text { Reliability }\end{array}$ & $\begin{array}{c}\text { Average Variance } \\
\text { Extracted (AVE) }\end{array}$ \\
\hline Company Side Risk & 0.895 & 0.894 & 0.631 \\
\hline Customer Side risk & 0.862 & 0.862 & 0.609 \\
\hline Environment side risk & 0.87 & 0.87 & 0.575 \\
\hline Logistics Performance & 0.841 & 0.837 & 0.579 \\
\hline
\end{tabular}

\section{Correlation of Discriminant validity}

Below is the table of this criterion for examination of discriminant validity which was introduced by Fornell \& Larcker (1981). The items of the construct should have variances among these more than the lying on other particulars of the constructs.

\begin{tabular}{|c|c|c|c|c|c|}
\hline Constructs & LP & SCUR & company & customer & environment \\
\hline LP & 0.781 & & & & \\
\hline SCUR & 0.591 & 1.000 & & & \\
\hline Company & 0.639 & 0.748 & 0.795 & & \\
\hline Customer & 0.628 & 0.764 & 0.878 & 0.781 & \\
\hline environment & 0.764 & 0.746 & 0.916 & 0.871 & 0.758 \\
\hline
\end{tabular}

Model Evaluation and Hypothesis Testing

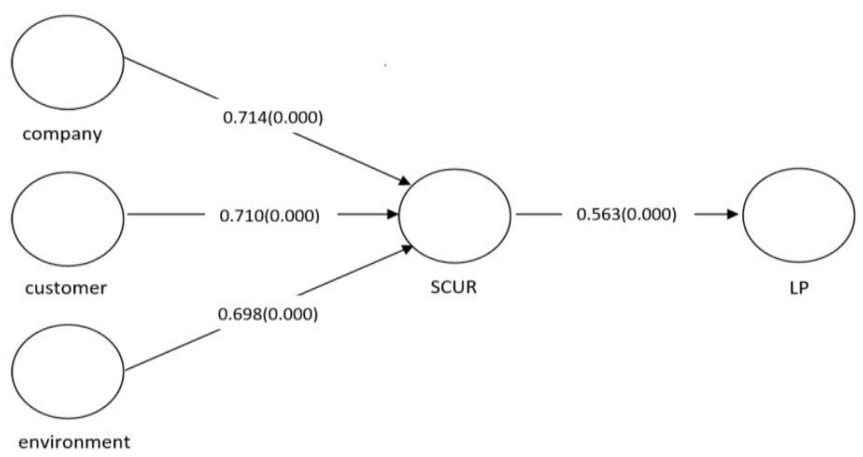


The hypothesis testing and model evaluation performed by PLS structure equation modeling. The results are significant and positive with supply chain uncertainty and risk i.e. (0.000), (0.000) and (0.000) respectively. The results are presented and it shows that the value of supply chain uncertainty and risk is (0.000) which is significant and shows positive relationship with logistics performance. According to the below mentioned figure of SEM model it represents the relationship between the independent variables to dependent variables by the medium of supply chain uncertainty and risk. The beta values of all the independent variables is positive which significantly impacting on supply chain uncertainty and risk.

\begin{tabular}{|l|c|c|c|l|}
\hline \multicolumn{1}{|c|}{ Hypothesis } & $\begin{array}{c}\text { Standard Deviation } \\
\text { (STDEV) }\end{array}$ & $\begin{array}{c}\mathrm{T} \\
\text { values }\end{array}$ & $\begin{array}{c}\mathrm{P} \\
\text { values }\end{array}$ & Decision \\
\hline SCUR -> LP & 0.046 & 12.351 & 0.000 & Supported \\
\hline SCUR -> company side risk & 0.039 & 18.496 & 0.000 & Supported \\
\hline SCUR -> customer side risk & 0.037 & 19.422 & 0.000 & Supported \\
\hline SCUR -> environment risk & 0.036 & 19.478 & 0.000 & Supported \\
\hline
\end{tabular}

The above testing of hypothesis shows the relationship between the variables have positive relationship and the $p$ value of all the variables is less than 0.05 which has been confirmed that the variables that were took out for the study has significantly impact on logistics performance. Therefore we conclude that the hypothesis of the study has been accepted so it would recommend the factors of customer side risk, company side risk and environment risk have significantly impact on supply chain uncertainty which definitely impact to the logistics performance of the courier companies.

\section{DISCUSSION}

The study relies in finding the effect of the customer risk, company risk and environmental risk on the supply chain activities, however, the statistical findings clearly evaluates that there are a significant effect of all the risk related factors on supply chain, however, the researcher has rejected the null hypothesis and suggests that the alternative hypothesis has been proved. Moreover, qualitative findings provide a clear understanding and evidence of the fact that logistics plays an essential role in increasing the success of the business. In addition, the discussion clearly reveals an overview of the achievement of logistics in the courier industries. Company risk is the most notable factor that relates to the internal risk factors of the company however, customer risk relates to the external risk of the company.

The results in the study reveal that there has been a significant impact of each of the independent variables including customer side, company side and environment side risk on the logistics performance of the company. The results seem to be different from the Australian study as the risk factors regarding each of the independent variable is different and the non-financial factors are quite different which varies the results (Wang, 2018). The following table will show the difference in the results of the Australian and Pakistan Courier Industry.

\begin{tabular}{|l|l|}
\hline Findings of Australian Courier Industry & Findings of Pakistan Courier Industry \\
\hline $\begin{array}{l}\text { Supply chain uncertainty has negative effect } \\
\text { on logistics performance. Moreover, the }\end{array}$ & $\begin{array}{l}\text { Supply chain uncertainty has significant and } \\
\text { positive impact on logistics performance and } \\
\text { greatest impact of supply chain uncertainty } \\
\text { the greatest impact of supply chain } \\
\text { and risk was from outside company in the } \\
\text { Ancertainty and risk was from environmental } \\
\text { side in the Pakistan courier industry }\end{array}$ \\
\hline The standardized value of beta is negative & The standardized value of beta is positive \\
\hline
\end{tabular}




\section{CONCLUSION}

The study aims at providing a notable evaluation on the customer risk, company risk and economic risk on the supply chain department of the courier industry in Pakistan. However, the study emphasizes that there is a significant effect of all these risks on the logistics performance of the company that directly interrelates with the company progress and success. In addition, the study discusses that the important factors regarding the risks related to the customers, company, and environment. The study also emphasizes the healthy recommendations that could help the company to tackle the major supply chain failures and risk related to supply chain activities.

The findings of the study showed that the beta values of all the independent variables is positive which is significantly impacting on supply chain uncertainty and risk. The positive value of Beta showed that there is a positive relationship among the variables and the greater impact on the logistics performance is expected to come from environmental side ( $t$-value $=19.47$ ). The positive value of beta of all the variables showed the positive relation among the factors. As discussed that supply chain management must be always safe and secure, the ideas and strategies to tackle with the consequences of the supply chain have been discussed briefly (Nordas et al., 2006). The discussion states that the logistics are the main tool which helps in maximizing the profit by trading the goods and services from the manufacturing point to the main ends hence it has several aspects that impose difficulty and obstruction at each stage. These hurdles and obstacles include the custom management, geographic and environmental barriers, and complexity in the procedural requirements, therefore, the physical inspection of the tool is an important activity to be implemented.

In this contemporary world, courier industry has been playing well and the competition has been seen to be increased in the trading activities, therefore, the courier industry must make the focus on the logistic performance and infrastructure to make it possible regarding the proper integration of the activities to reduce logistics related constraints. In addition, with respect to customer risk, there are some of the customers, who seems to be a danger for the company and might be a big risk that affects the company performance. The type of risk seems to be associated between the customers and the company and the operations interrelated to the courier company. It is the foremost duty of the company to deliver good quality goods from the point of origination to the point of destinations (Gani, 2017).

As per the view of the discussion, it has been also noted that the infrastructure in logistics tends to play an important role in making long-term effects for the company. This is the reason that the courier industry must have to focus on the national and international logistics to build up the mechanism and connections among the departments (Feng et al, 2012; Arvis et al., 2014). Moreover, for the courier industry there is a strict need of making the global logistics efficient hence this helps in increasing the level of customer satisfaction and integration with the economic growth (Bai et al., 2004).

Pakistan does not have a well-organized logistic system thus the company must support in making the transportation strong (Zuraimi et al., 2013). With respect to the supply chain, the complexities have been increasing with the passing time and associated risk with the customers, company, and environment. It has been also noted that there are some of the direct players of the supply chain management that includes the retailers, customers and the producers thus all these players could be the reason of risk in the logistics management, therefore, all of them must be managed successfully. 
Logistics infrastructure in macro level requires long-term sustained efforts of regional and national governments (Feng et al., 2012; Arvis et al., 2014). Thus, it is natural that Building regional and national logistics as dependable linkage mechanisms becomes one of the top industrial policy priorities.

The logistics under both the aspects either domestic or global needs an efficient network to deliver the products and services timely. In order to this, the long-term plans are made to enhance the network which includes the connection with all kinds of transportation networks such as air, land water etc. to boost the economic growth of the country (Bai et al., 2004). Countries with well-organized logistics systems have excellent maritime transportation systems, road systems, waterways, and rail systems (Zuraimi et al., 2013). Finally, the study done is only focusing on the Pakistan courier industry and any generalization about the other industries must be prepared with attentiveness. As per the fact that the supply chain uncertainty also impacts other areas except for the logistics capability, the researcher suggests the future scholars investigate the resource-based approach for eliminating the supply chain uncertainties by taking it to the different contexts.

\section{Future Recommendations}

With respect to the entire study, there is a certain risk that creates a bad impact on the supply chain management of the company hence the best recommendations are as follows

- The implementation of enterprise risk management has been considered as the notable suggestions to tackle the risk

- The implication of the strategic requirements including the insurance and limitations could help in reducing supplier's risk

- The financial stability and visibility of the suppliers must be strong

- The customers must be provided with significant services as they might become a major risk for the company

- The supplier assessment evaluation could be also useful in identifying the supply and environmental risks.

The study could be further explored in the future however, the disruptions in the supply chain and the decision making regarding the supply chain could be made into consideration for the future study. The researchers could study in detail about the quantitative and qualitative technique of supply chain management and must examine other companies of Pakistan to extend the area of research. In addition, some theoretical perspectives must be reviewed to consider the opportunities for future concerns regarding supply chain risk. Due to the fact that the supply chain uncertainty also impacts other areas other than the logistics capability, the study suggests the future scholars examine the resource-based approach for eliminating the supply chain uncertainties by taking it to the different contexts.

\section{Research Implications}

The present study focuses on the Pakistan courier industry. This might limit the implication of the findings in the different countries. Though, the research model is valid in the different context. The findings have offered the direction in the incorporation of the strategies to handle the supply chain uncertainty and risk and enhance the logistics performance. The findings may also serve to enlighten both the academic and practitioners to know and give central focus to the supply chain uncertainty and risk in the courier industry. 


\section{REFERENCES}

Ahmed, A., \& Ahsan, H. (2011). The contribution of the services sector in the economy of Pakistan. Working Papers \& Research Reports, 2011.

Arvis, J., Saslavsky, D., Ojala, L., Shepherd, B., Busch, C. \& Raj, A. (2014). Connecting to Compete 2014 - Trade Logistics in the Global Economy: The Logistics Performance Index and Its Indicators, World Bank, Washington, DC

Aven, T. (2011). Quantitative Risk Assessment: The Scientific Platform, Cambridge University Press, New York.

Bai, C., Du, Y., Tao, Z. \& Tong, S.Y. (2004). 'Local protectionism and regional specialization: China's industries', Journal of International Economics, Vol. 63, No. 2, pp.397-417.

Chin, W. W., Marcolin, B. L., \& Newsted, P. R. (2003). A partial least squares latent variable modeling approach for measuring interaction effects: Results from a Monte Carlo simulation study and an electronic-mail emotion/adoption study. Information Systems Research, 14, 189-217.

Chow, G., Heaver, T. D., \& Henriksson, L. E. (1994). Logistics performance: definition and measurement. International journal of physical distribution $\mathcal{E}$ logistics management, 24(1), 17-28.

Christopher, M \& Lee, H. (2004). 'Mitigating supply chain risk through improved confidence', International Journal of Physical Distribution \& Logistics Management, vol. 34, no. 5, pp. 388-96.

Christopher, M. (1998). Logistics and supply chain management: strategies for reducing cost and improving service, 2nd edn, Financial Times Management, London.

Cohen, S \& Roussel, J. (2005). Strategic supply chain management: the five disciplines for top performance, McGraw-Hill, NY.

Coyle, JJ, Langley, CJ, Gibson, BJ, Novack, RA \& Bardi, EJ. (2008). Supply chain management: a logistics perspective, 8th edn, South-Western Cengage Learning, $\mathrm{OH}$

Dawn News. (2011). Removal of hurdles in logistics, supply chain sought. Retrieved from https://www.dawn.com/news/675311.

Feng, M., Mangan, J. \& Lalwani, C. (2012). ‘Comparing port performance: Western European versus Eastern Asian ports', International Journal of Physical Distribution and Logistics Management, Vol. 42, No. 5, pp.490-512

Fornell, C., \& Larcker, D. F. (1981). Structural Equation Models with Unobservable Variables and Measurement Error: Algebra and Statistics. Journal of Marketing Research, 18, 382-388. http://dx.doi.org/10.2307/3150980

Gani, A. (2017). The Logistics Performance Effect in International Trade. The Asian Journal of Shipping and Logistics, 33(4), pp.279-288.

Helena, F. (2012). 'Performance management in supply chains: logistics service providers' perspective', International Journal of Physical Distribution \& Logistics Management, vol. 42, no. 3, pp. 296-311.

Hudson, W.R., Haas, R. \& Uddin, W. (1997). Infrastructure management: Integrating design, construction, maintenance, rehabilitation, and renovation (Vol. 9). New York: McGraw-Hill.

Jüttner, U, Peck, H \& Christopher, M. (2003). Supply Chain Risk Management: Outlining an Agenda for Future Research, International Journal of Logistics Research and Applications 6(4), pp. 197-210

Kimmons, R. (2018). Logistics Performance. Retrieved from https:/ / smallbusiness.chron.com/logistics-performance-24822.html

Knight, FH. (1921). Risk, Uncertainty and Profit, Houghton Mifflin Company, Boston, New York.

Leighton, RM. (2012). Logistics, Oxford University Press, UK

Manuj, I \& Mentzer, JT. (2008). 'Global supply chain risk management', Journal of Business Logistics, vol. 29, no. 1, pp. 133-55. 
McManus, H \& Hastings, D. (2006). 'A framework for understanding uncertainty and its mitigation and exploitation in complex systems', IEEE Engineering Management Review, vol. 34, no. 3, pp. 81-.

Miller, KD. (1992), A Framework for Integrated Risk Management in International Business, Journal of International Business Studies 23(2), p. 311.

Murugesan, P, Natarajan, T \& Lakshminarayanan, M. (2013). 'Assessment of supply chain risk: scale development and validation', benchmarking: an International Journal, vol. 20, no. 1, pp. 79-105.

Nordas, H. K., Pinali, E., \& Grosso, M. G. (2006). "Logistics and time as a trade barrier”, OECD Trade Policy Working Paper, No. 35, OECD, Paris

Olson DL, \& Wu D. (2011). Risk management models for supply chain: a scenario analysis of outsourcing to China. Supply Chain Manag Int J; 16(6): 401-8.

Pichet, K \& Shinya, H. (2008). 'Evaluating the logistics performance of intermodal transportation in Thailand', Asia Pacific Journal of Marketing and Logistics, vol. 20, no. 3, pp. 323-42. pp. 397-417.

Prater, E. (2005). A Framework for Understanding the Interaction of Uncertainty and Information Systems on Supply Chains, International Journal of Physical Distribution \& Logistics Management 35(7), pp. 524-539.

Rani, P.D.L. (2015). Supply Chain Collaboration Practices (A Study on Manufacturing CompaniesEthiopia).

Richard, W \& Rein, J. (2004). 'Customer perceptions of logistics outsourcing in the European consumer goods industry', International Journal of Physical Distribution \& Logistics Management, vol. 34, no. 8 , pp. $628-44$.

Rodrigues, VS, Potter, A \& Naim, MM. (2010). 'The impact of logistics uncertainty on sustainable transport operations', International Journal of Physical Distribution \& Logistics Management, vol. 40, no. 1/2, pp. 61-83.

Rodrigues, VS, Potter, A \& Naim, MM. (2010). 'Evaluating the causes of uncertainty in logistics operations', International Journal of Logistics Management, vol. 21, no. 1, pp. 45-64

Rodrigues, VS, Stantchev, D, Potter, A, Naim, M \& Whiteing, A. (2008). 'Establishing a transport operation focused uncertainty model for the supply chain', International Journal of Physical Distribution \& Logistics Management, vol. 38, no. 5-6, pp. 388- 411.

Shapira, Z. (1987). 'Managerial Perspectives on Risk and Risk Taking', vol. 33, no. 11, pp. 1404-18

Simangunsong, E, Hendry, LC \& Stevenson, M. (2012). 'Supply-chain uncertainty: a review and theoretical foundation for future research', International Journal of Production Research, vol. 50, no. 16, pp. 4493-523.

Stewart, N. (2011). Australian Logistics Challenges and Ways to Overcome Them.

Tang, CS. (2006). 'Perspectives in supply chain risk management', International Journal of Production Economics, vol. 103, no. 2, pp. 451-88.

Thompson, B. (2004). Exploratory and confirmatory factor analysis: Understanding concepts and applications. American Psychological Association.

Waters, D (2011). Supply Chain Risk Management Vulnerability and Resilience in Logistics, 2nd ed. edn, Kogan Page, London.

Zuraimi, A., Yaacob, M. \& Ibrahim, M. (2013) 'Logistics development in Malaysia East Coast Region: infrastructure, constraints and challenges', International Journal of Trade, Economics and Finance, Vol. 4, No. 5, pp.325-330.

$$
\text { --0-- }
$$

